\title{
HABLEMOS DEL DERECHO A LA VIDA
} LET'S TALK ABOUT THE Right TO STILLING Alive

\author{
Hernán A. Olano García*
}

Resumen: Con el objetivo de resaltar el valor del derecho fundamental dentro de los derechos fundamentales, de acuerdo con la Constitución Política de Colombia (y a otras constituciones) y, dentro de su línea de investigación en historia de las instituciones-I, el autor realiza algunas reflexiones acerca del derecho a la vida, siguiendo una metodología deductiva, de acuerdo con los aspectos más importantes que tanto la doctrina, como la jurisprudencia le han aportado para estructurar el artículo en varios acápites como: (i) su carácter sagrado, (ii) ¿Un derecho a la muerte?, (iii) la dignidad ontológica de la vida y (iv) el día de la vida, que reconoce la protección de este derecho de toda persona, como fundamento y fin de todo el orden social justo. La conclusión principal a la que se llega es el valor sagrado y jurídico de la vida humana, dotada de trascendencia en el ordenamiento positivo por su origen natural.

Palabras clave: Persona, eutanasia, dignidad humana, aborto, derechos fundamentales

Abstract: With the objective of highlighting the value of the fundamental right within the fundamental rights, according to the Political Constitution of Colombia (and other constitutions) and, within its line of research in history of the institutions-I, the author makes some reflections on the right to life, Following a deductive methodology, according to the most important aspects that both the doctrine and the jurisprudence have contributed to structure the article in several sections such as: (i) its sacredness, (ii) a right to death?, (iii) the ontological dignity of the Life and (iv) the day of life, which recognizes the protection of this right of every person, as the foundation and end

\footnotetext{
* Doctor en Derecho Canónico, Magíster en Relaciones Internacionales y Magíster en Derecho Canónico y especialista en Bioética, Derechos Humanos, Derecho Administrativo y Gestión Pública, Liderazgo Estratégico Militar, Gestión Ambiental y Desarrollo Comunitario y Derecho Constitucional. Director y Profesor del Programa de Humanidades en la Facultad de Filosofía y Ciencias Humanas de la Universidad de La Sabana. Proyecto Din-Hum-052/2015. hernan.olano@unisabana.edu.co

El presente trabajo fue presentado dentro del I Congreso de Derecho \& Humanidades en homenaje a Juan Larrea Holguín, realizado del 30 de junio al 2 de julio de 2016. Para publicarse siguió el proceso ordinario de la Revista con revisión de pares con doble ciego.
} 
of the whole just social order. The principal conclusion is the sacred and juridical value of human life, endowed with transcendence in the positive ordering by its natural origin.

Keywords: Person, euthanasia, human dignity, abortion, fundamental rights

Sumario. I. Introducción. II. El carácter sagrado de la vida. III. ¿Un derecho a la muerte? IV. Dignidad ontológica de la vida. V. El día de la vida. VI. Conclusiones. Referencias.

\section{INTRODUCCIÓN}

Se trata de presentar aquí una reflexión por la defensa del derecho a la vida, que siempre está en peligro de vulneración, razón por la cual quiero recordar una declaración que como académico, me hace estar en plena sintonía con lo que afirmó hace años el Santo Padre, Juan Pablo II:

«Así pues, no tiene razón de ser esa mentalidad abandonista que lleva a considerar que las leyes contrarias al derecho a la vida - las leyes que legalizan el aborto, la eutanasia, la esterilización y la planificación de los nacimientos con métodos contrarios a la vida y a la dignidad del matrimonio - son inevitables y ya casi una necesidad social. Por el contrario, constituyen un germen de corrupción de la sociedad y de sus fundamentos» (2000).

\section{Y Mons. Juan Larrea, expresó:}

«La batalla por la vida comenzó en los albores de la humanidad. En el primer episodio parece vencer Satanás, inspirador del fratricidio cometido por Caín. Sigue una cadena pavorosa de violencias que degradan al hombre hasta el punto que la Biblia describe de manera antropomórfica - adecuada a nuestro modo de sentir y hablar "que el Señor se arrepintió de haber creado al hombre" y envió el diluvio para extinguir a la raza pecadora. Solo Noé y su familia permanecieron fieles al Autor de la vida y recibieron de El nuevamente la misión de repoblar la faz de la tierra.

Quien no tenga fe, quien no acepte que hay un Señor del universo, un Creador de la vida, y un Redentor de todo hombre, es lógico que siga las sugerencias diabólicas, que le parezca razonable sacrificar las vidas humanas — nacidas o no nacidas - al placer, al dominio de los demás, a la conquista del mundo.

La lógica de los sostenedores del aborto puede presentarse como aceptable: si no hay Dios, si el hombre es un animal más, un producto químico, entonces, ¿Por qué he de respetar la vida, cuando me molesta, cuando me exige sacrificar un placer o limita la ambición de poseer y dominar?» (Larrea Holguín, 2003, p. 61).

Igualmente, expresó el doctor Juan José García Posada que «un periodismo que se ponga al lado de la corriente abortista, claudica en sus valores 
éticos fundamentales. Es la negación de la vocación de defensa de los que no tienen voz» (García Posada, 2013, p. 25). Si bien es cierto la vida es un aspecto que tratan muy a fondo las religiones, no sólo la católica, esto bajo ningún aspecto quiere significar que sea un tema de exclusividad religiosa.

Tal como lo anota el estadounidense Ronald Dworkin, a los ateos también les afectan los posibles problemas que derivan de tan debatido tema, cual es la vida, y si los afecta, es, precisamente por el valor intrínseco que tiene la vida, valor derivado de la naturaleza humana, la cual no es diferente para los hombres religiosos y para los ateos, sino que por el contrario designa lo que es común a todos los hombres: la vida como valor que es sagrado y por lo tanto inviolable

La vida no pertenece a un ámbito privilegiado, pertenece tanto a la biología como a la sociología, tanto al religioso como al jurídico, y esto, porque al ser la vida el ser del viviente ya al hablar de vida humana necesariamente nos estamos refiriendo a derechos, pues es imposible hablar de persona sin derechos y de derechos sin persona. Además, es la naturaleza humana la que fundamenta la igualdad, derecho amparado con celo prácticamente en todas las constituciones $^{1}$; igualdad que se predica de todo ser humano y que es fundamento y fin esencial de toda norma suprema estatal.

La vida, como es sabido por todos, es un bien debido a una persona determinada, desde su inicio, esto es, desde el momento de la concepción ${ }^{2}$, hasta la muerte, en virtud de un título jurídico el cual es la naturaleza humana y por esta misma razón es por la que también pertenece al ámbito del derecho, pues si tiene un título jurídico natural estamos hablando de un bien jurídicamente tutelado, reconocido por la ley positiva ${ }^{3}$.

Siguiendo con el aporte de Ronald Dworkin, la vida es intrínsecamente importante, no por ser algo instrumental, por depender su valor de la utilidad, de su capacidad de ayuda a las personas, etc., sino por algo mucho más trascendental y realista: por ser un valor independiente de lo que las personas quieren, disfrutan o necesitan. Por tener un valor inherente, cosa que no predican únicamente las personas religiosas, pues por ser una verdad establecida en virtud de la naturaleza humana es común a todos y por lo tanto debe ser respetada, por todos, no obstante las dificultades que las creencias religiosas o políticas posean las personas para resignificar el valor de la vida como bien trascendente.

\footnotetext{
${ }^{1}$ Para muestra de botón, cfr. Constitución de Colombia, art. 13, y de Ecuador, art. 11.

${ }^{2}$ La Corte Constitucional de Colombia, en la sentencia C-133 de 1994, reconoció que la vida comienza desde el momento de la concepción al citar al reconocido genetista Jéröme Lejeune.

${ }^{3}$ En el caso colombiano, por el art. 11 de la Constitución Política.
} 


\section{EL CARÁCTER SAGRADO DE LA VIDA}

Parecería que la vida no tiene un carácter sagrado, porque el principio de la autonomía, citado por Dworkin, permite que si una persona ha expresado claramente su deseo de morir puede hacerlo, la vida puede ser violada, luego la vida no tiene un carácter sagrado. Sin embargo, el mismo Ronald Dworkin dice en El Dominio de la Vida. Una discusión acerca del aborto, la eutanasia y la libertad individual, que «la elección de una muerte prematura es el insulto más grande posible al valor sagrado de la vida» $(1994$, p. 280$)$ y agregaba que algo es sagrado o inviolable «cuando su destrucción deliberada deshonraría lo que debe ser honrado» (p. 101).

De esta forma lo reconocen las constituciones. Por ejemplo, nuestra Constitución Política, por lo menos formalmente, consagra que «el derecho a la vida es inviolable» (art. 11). De ahí que la vida, según lo expuesto anteriormente, tenga un carácter sagrado, independientemente de la religión que se profese y de las consideraciones personales que pueda tener cada persona sobre el particular, pues como se ha dicho en reiteradas ocasiones, el carácter sagrado de la vida está dado no subjetivamente, sino que por el contrario por el valor intrínseco que la misma tiene, esto es, por un carácter objetivo que emana de la naturaleza misma.

Así las cosas, la vida es intrínsecamente sagrada y así está reconocida en muchas cartas políticas, razón por la que no se ve motivo alguno para que pueda ser amenazada, lesionada o violada por razones de índole meramente subjetivas. Por el contrario, debe ser respetada de un modo puramente objetivo de acuerdo con las necesidades o exigencias de la naturaleza propia del hombre, la racional.

El principio de la autonomía no es absoluto, pues se estaría desconociendo el orden social justo, que está dado por la naturaleza humana, estructura óntica u ontológica del hombre.

Al hablar del principio de la autonomía, nos referimos obviamente a la libre determinación del hombre en sus actuaciones, pero teniendo siempre presentes los límites que muchas veces suelen señalar las constituciones y otras normas de inferior rango: el respeto a la dignidad humana la igualdad, la solidaridad, limites que a su vez son fundamento y fines esenciales de la misma y por consiguiente de nuestro Estado social de derecho.

De lo anterior resulta claro que no es viable hablar de libre disposición de la vida, en virtud del principio de la autonomía pues el carácter sagrado de la vida implica supremacía sobre los demás principios, al igual que respeto sagrado de la vida o lo que es lo mismo su inviolabilidad. 


\section{III. ¿UN DERECHO A LA MUERTE?}

Al hablar de un derecho a morir, de plano se está negando el derecho a nacer. El derecho a la vida implica ser y existir de acuerdo con la dignidad de la persona, esto es, de acuerdo con el crecimiento ontológico en la jerarquía del ser por participación. «En una trascendencia hacia el Ser por esencia», como lo aseguraba el profesor Francisco José Herrera Jaramillo (1995, p. 12).

El derecho a la vida, derecho fundamental por excelencia, es tutelado por todas las constituciones contemporáneas como un derecho inviolable, lo cual no significa que los demás derechos sí lo sean; sino que la Constitución le está dando un especial reconocimiento al carácter sagrado que la vida misma, el cual está dado por el valor intrínseco de ella.

El derecho a la vida es irrenunciable. Por lo tanto, no puede hablarse de derecho a morir. Si fuese posible hablar de que el derecho a la vida es renunciable, se estaría negando el orden social justo que propugna la constitución, pues, la vida es un bien jurídicamente tutelado que constituye un derecho en razón de que es justa, debida y que tiene un título jurídico, el cual es la naturaleza humana, por esto, es imposible hablar de derecho a la muerte, no tiene fundamento jurídico alguno. Herrera expresaba:

«El derecho a la muerte se tiene en potencia, y contestamos: si es en potencia, no está en acto, luego no es derecho propiamente hablando, sino expectativa de tener un derecho, lo que indica que no tiene asidero jurídico, no existe, entonces no es» (1995, p. 14).

Cada vida humana es una trayectoria dinámica, viva, amplia y plural, dice el psiquiatra español Enrique Rojas (2012, Pág.129).

Entonces, no puede hablarse de derecho a la muerte en el sentido de que la muerte para el ser es el no ser, la nada; por consiguiente se configura una ausencia de objeto jurídico, lo que está inhabilitándolo para que sea tutelado.

Si bien es cierto el derecho al libre desarrollo de la personalidad es tutelado por constituciones como la colombiana, ella misma impone un límite para el ejercicio de dicho derecho el cual imponen los derechos de los demás y el orden jurídico. Obviamente dentro de estos límites está comprendido en primer orden el derecho a la vida, y la dignidad de la persona humana en cuanto principio fundamental del Estado.

Es indudable que en la familia es donde se aprende a plantear adecuadamente la vida (Rojas: 2012, 129), pero, el desconocimiento del valor de ésta y de sus valores positivos, son una desafortunada tendencia actual por la desarticulación de esa base fundamental de la sociedad.

Además, el derecho a la vida, lo tiene toda persona independientemente de la religión que profese. Si llegásemos a afirmar que prima la libertad de cultos 
sobre la vida, estaríamos desconociendo que la persona es el fundamento y fin de todo el orden social justo.

\section{DIGNIDAD ONTOLÓGICA DE LA VIDA}

El art. 1 de la Carta Constitucional colombiana, consagra que el Estado se funda en el respeto a la dignidad humana; por tanto, la persona que sufra de una enfermedad incurable está, para la Corte Constitucional, disminuida en dignidad, entonces existe un supuesto derecho a la muerte digna en aras de respetar la dignidad humana.

Sin embargo, la dignidad de la que habla la misma norma superior es la ontológica, que es la perfección que tiene todo ser humano en tanto ser creado, es el mismo estatuto ontológico de la persona humana. Por tanto, la perfección del ser es aquello que lo ordena siempre al bien, en virtud de la naturaleza humana, entonces no es posible afirmar que de acuerdo con el respeto a la dignidad se pueda proclamar un derecho a la muerte.

Esa dignidad ontológica jamás se desmejora, ni se vuelve inferior, ni nada por el estilo, y hace referencia a la que tiene todo ser humano; es la que hace posible el principio de la igualdad, tutelado por casi todas las constituciones políticas y sus ordenamientos complementarios, pues, por la dignidad es por la que podemos hablar de hombres iguales en esencia. Por eso es que en ningún momento puede hablarse de que quitarle la vida a otro, aun previo consentimiento, sea licito, ni natural ni legalmente.

Los fines hacia los cuales está ordenada la persona, en razón de su dignidad, son todos aquellos que se adecuan a su naturaleza racional, que lo perfeccionan, que lo hacen mejor (dignidad moral). ¿En qué sentido se puede decir que causarle la muerte a otro sea bueno o perfeccione al hombre? Muchos dirán en este momento que no es tan grave quitarle la vida a otro cuando medie el consentimiento de la víctima, pero aun así ¿está éste comportamiento de acuerdo con los fines de la naturaleza humana? De ninguna manera.

No existen fundamentos de ninguna clase para hablar del derecho a una muerte digna. Cosa diferente es cuando hablamos de eutanasia pasiva ${ }^{4}$, que ya no constituye un atentado contra la dignidad, sino que por el contrario está conforme con ella, pues nadie está obligado a soportar la vida por medios extraordinarios, pues al igual que existe el deber de aceptar la vida tal como es, también tenemos el deber de aceptar nuestra propia muerte, tal y como nos llegue.

\footnotetext{
${ }^{4}$ Aquella contraria a la expresión eutanasia activa, que denomina el acto deliberado de dar fin a la vida de un paciente, por su propio requerimiento o a petición de parte.
}

Ius Humani, v. 5 (2016), p. 214 
Por todo lo anterior, es claro que no hay razón alguna para justificar, ni tolerar la eutanasia. Puesto que todo está resumido en el carácter sagrado de la vida, en el valor intrínseco de ésta, lo cual genera, su inviolabilidad.

\section{EL DÍA DE LA VIDA}

El día de la vida debería ser todos los días del año. El Congreso de Colombia, por medio de la ley 1056 de 2006 proclamó, en su art. 7, el día 6 de noviembre de cada año como Día Nacional del Derecho a la Vida. En otros países hay fiestas semejantes, sobre todo el 25 de marzo.

¿Qué implicaciones tiene esta celebración tan ignorada? El que los establecimientos educativos públicos y privados, al igual que la rama judicial, tienen la obligación de conmemorarlo con la realización de foros, conferencias, talleres y jornadas de reflexión referentes al derecho a la memoria, los derechos humanos y el respecto a la vida. Sin embargo, nunca la vida se ha visto más amenazada por las propias instituciones a las que se les obliga protegerla.

Incluso en la plazoleta del Palacio de Justicia, según mandato de la mencionada disposición, debe existir un monumento a la vida, cuyo carácter sagrado e inviolabilidad, es reconocida en el art. 11 de la Carta colombiana. La investigación con seres humanos, los trasplantes de órganos, la manipulación del código genético, la fecundación asistida, la prolongación artificial de la vida y otras posibilidades de la técnica, han suscitado problemas jurídicos y éticos desconocidos hasta ahora, o tratados sin dignidad y con la simpleza de lo artificial o superfluo.

Algunos sugieren que la dignidad humana no es una realidad objetiva, sino que varía según las circunstancias que rodean la vida, o según las valoraciones o las estimaciones que sobre ella se realicen.

\section{ConclusioneS}

Restringiendo el tema a la salud, a ese deber de procurar su cuidado integral, con la dimensión ética - cuyo núcleo esencial es la plenitud vitalque para ella impone la Constitución, concluimos:

1. El derecho a la vida es un derecho fundamental por ser inherente a la dignidad de la persona humana, en tanto que constituye parte integral de su ser.

2. El derecho a la salud es un derecho derivado de la vida, porque la conexidad entre la salud y la vida es evidente, ya que la salud es un objeto jurídico concreto del derecho a la vida. 
3. Este derecho se tiene desde la concepción hasta la muerte. Implica una acción de conservación y otra de restablecimiento que conlleva a la necesaria labor preventiva contra los posibles atentados a la salud, así como a la protección de la normalidad orgánica funcional física y mental, y a su restablecimiento cuando se presente inestabilidad orgánica funcional y psíquica en el Ser y su plenitud.

4. Lo anterior implica hacer uso de los medios ordinarios y proporcionados para la prevención o recuperación de la salud, teniendo en cuenta la situación concreta del enfermo y, sin perder su carácter fundamental, tiene un carácter asistencial o prestacional.

\section{REFERENCIAS:}

Dworkin, R. (1994). Life's Dominion: an argument about Abortion, Euthanasia and individual Freedom. Nueva York: Vintage Books.

García Posada, J.J. (2013). La vigilia de la razón. Medellín: Pontificia Universidad Bolivariana.

Gaymard-Lejeune, C. (2000). Life is a blessing. París: Jerome Lejeune Foundation.

Herrera Jaramillo, F. J. (1995). Filosofía del Derecho. Bogotá: Pontificia Universidad Javeriana.

Juan Pablo II (2000). Discurso del Santo Padre Juan Pablo ii ante la Academia Pontificia para la Vida con motivo del V aniversario de la publicación de la Encíclica Evangelium Vitae. En https://w2.vatican.va/content/john-paulii/es/speeches/2000/janmar/documents/hf_jpii_spe_20000214_acd-life.html (recuperado el 1-XII-2016).

Larrea Holguín, J. (2003) Albores del Nuevo Milenio. Guayaquil: Poligráfica.

Olano García, H. A. (2010). Constitución política de Colombia - comentada y concordadaBogotá, D.C.: Doctrina y Ley.

República de Colombia. Constitución Política.

República del Ecuador. Constitución Política, art. 13.

Rodríguez, C. (2010). La decisión judicial. El debate Hart-Dworkin. Bogotá: Universidad de los Andes.

Rojas, E. (2012). El hombre light. Bogotá: Procodes. 